\title{
Apuntes breves y maravillosos sobre
}
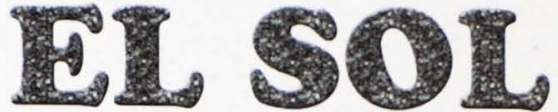

\author{
Por: Jorge Barraza Ibarra
}

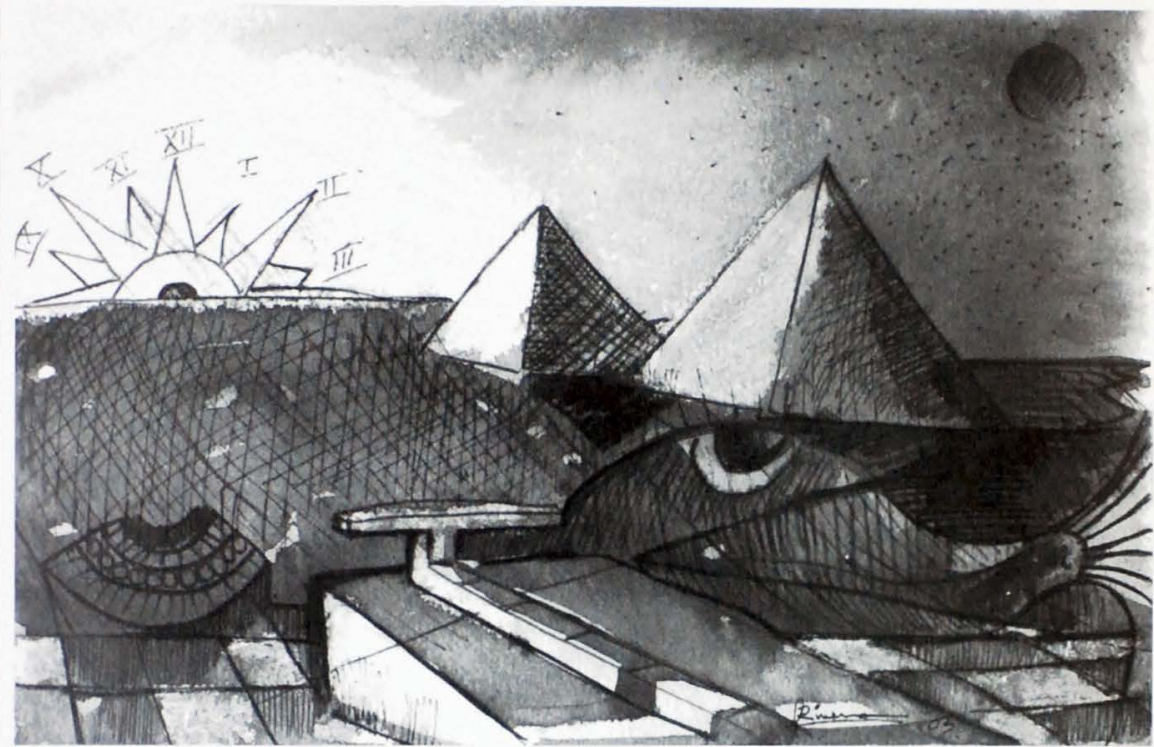

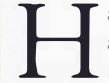

ace aproximadamente treinta mil años, el hombre anoraba el curso del sol y de la luna, asi como las

sucesiones de los dias y las estaciones, sobre placas de hueso o sobre platos de guijarros. Estos descubrimientos que arrojan nuevas luces en el lenco c.unino del hombre hacia la civilización, se deben al investigador americano Alex.under Marshack, investigador del l'eabody Muscum de la Universidad de Harvard.

entorido

ento

entor

enior

entor

entor

entort

entorint

Gulvitit

Los resultados de esta investigación, pacientemente transcurrida durante un lapso de diez años, se fundamentan en miles de objetos encontrados en excavaciones arqueológicas realizaclas en toda Europa. Los primitivos calendarios de la humanidad se encuentran en las obras de arte del Paleolítico superior, treinta y seis mil años antes de (.risto. El hombre Ciromagnon, nuestro más lejano ancestro, era consciente de la importancia del sol, y su papel de dispensador del calor y la vid.s.
L.as primeras formas para medir el ticmpo estaban basadas sobre observaciones del comportamiento de la sombra, que aumentaba o disminuia a medida que el sol atravesaba el cielo. Se llego así a identificar las diversas etapas de la jornada. Mis adelante, el hombre mejora este "reloj de sombra". en función de sus propias necesidades. la primera de esta mejoria ha sido atribuida a causas forruitas y universales.

Un alto tronco de árbol, limpio de ramas exteriores, con su sombra móvil es capaz de permitir la medida del tiempo, en forma más o menos duradera. En busca de una mayor comodidad, el hombre inventó utilizar un palo, largo y recto, que podia ser llevado de un lugar a otro, siempre con el mismo objerivo. Fin una segunda etapa, cuando se comenzó a sentir la necesidad de: una miyor precisión, el hombre aprendió a dividir y marcir los círculos formados por la sombra en segmentos mis pequeños, hasta llegar a inventar la meridiana. 
La capacidad racional para comprender la función del sol y sus efectos sobre la tierra, inicialmente está unida a referencias mágico-religiosas, que se reflejan en las poderosas construcciones megalíticas, levantadas durante el período Neolítico, 5000 años antes de Cristo. Junto al dolmen, grandes tumbas de piedra, fueron construidos verdaderos templos con funciones de observatorios solares y astronómicos; siendo el más famoso el de Stonenhenge, en Inglaterra.

Los ejes del templo, la colocación de las piedras en particular correspondencia con la posición del sol en los equinoccios, la época del año en la cual la duración del día es exactamente igual a la de la noche; generalmente los dias 21 de marzo y 22 de sepriembre; así también con la posición de los solsticios, días que constituyen el inicio del verano $y$ del invierno, que son a su vez, el más largo y el más corto del año, unidos a su vez a la disposición del altar central y la misma disposición concéntrica de los enormes círculos megalíticos, no dejan lugar a dudas.

Una casta de sacerdotes, que eran el mismo tiempo brillantes científicos, contribuía con importantes conocimientos prácricos a los agricultores, navegantes y demás pobladores. Con toda esa sabiduría fueron erigidos gigantescos alineamientos de menhires en Carnac, en Bretaña: 13 filas paralelas a lo largo de varios kilómetros, divididos en tres grupos con casi tres mil enormes piedras. En este caso, los alineamientos estaban orientados hacia el lugar donde el sol se levanta, hacia los equinoccios y los solsticios.

Siempre relacionadas con el sol, se encuentran algunas figuras geométricas grabadas en las placas de las rumbas megalíticas en Bretaña e Irlanda. En Newgrange, al norte de Dublín, en el valle del Boyne, en la gran tumba galería bajo túmulos circulares revestidos de piedras decoradas, el arqueólogo ingles Glyn Daniel ha reconocido en numerosas figuras en espiral y en círculos concéntricos, evidentes símbolos del sol, asociado al culto de los difuntos.

En las incisiones rupestres prehistóricas de Val Cámonica, en Lombardía, el disco solar aparece muchas veces. De acuerdo con algunos arqueólogos, el sol es el elemento esencial en la composición monumental de los Camuni, en donde asume un rol prominente en el periodo arcaico, a menudo aso- ciado a los animales, sobre todo a la cornamenta de los ciervos. El culto local se encontraba dividido entre la entidad celeste y las presas de la caza.

Agotada, aunque solamente en parte, las formas de magia primitiva inspiradas por el sol, encontramos el astro bajo formas de divinidades masculinas o femeninas, en el mundo mesopotámico y en las civilizaciones del vecino Oriente. En la Antigua Mesopotamia el sol era un dios justo que sabia disfrutar el ánimo de los hombres y castigar las acciones malvadas. Pero fueron los antiguos egipcios de la quinta dinastía, los que colocaron el sol dentro del Panteón de sus divinidades, reconociéndole la prestigiosa función de dios nacional y supremo. Ra era llamado el dios solar, que procede del cielo en su barca, recibiendo la dedicación de numerosos templos con la característica de un gran obelisco central, tomando como modelo el del santuario de Heliópolis.

Más tarde, el faraón Amenofis IV, marido de la bellísima Nefertiri, acentúo el culto exclusivo del disco del sol, llamado Atón, e impuso su adoración, haciendo destruir las imágenes de otras divinidades. Más complejos fueron los otros atributos conf eridos al astro por los antiguos griegos: el sol era ance rodo, padre y primero entre los dioses, omnipotente y supremo. También los dioses en el Olimpo tenían necesidad de su luz y calor, y le hacían sacrificios. Tenía el poder de dar la vista a los justos y castigar con la ceguera a los culpables; conceder sabiduría a los hombres, cuyas acciones las conocía en su totalidad.

El culto al sol se hace más solemne durante la época helenística: el sol habia llegado a ser una divinidad provista de un alma inmortal, infinitamente poderosa y sabia, en este período, las imágenes de la divinidad eran asumidas por formas humanas.

Para los etruscos, las ciencias adivinatorias eran tenidas en la máxima consideración y comprendía la subdivisión del espacio celeste en cuatro partes, cuyos vértices correspondian a los puntos cardinales. El sector oriental que veía el surgimiento y el tramontar del sol, era considerado beneficioso y poblado de divinidades terrestres y celeste positivas. 
entorno

entomo

entorino

entorno

entorino

enlorino

entoring

entorno

entorno

entorno

entorno

entorno

entorno

entorno

entorno

sitorno

entorino

entorno

entorna

enlorine

entorno

entorna

entorno

entorino

entorio

entorno

entorino

entorno

entorna

entorno

entorno

entoring

enlorino

entorino

entorno

entorno

entorne

entorno

entorino

entorna

entorno

entorno

enilorino

entorno

entorno

enterno

entorno

sntorno

entorno

entorno

entorino

entorno

entorno

entorno

entorno

entorno

enlorino

entoEntorno

Para los romanos, el sol era venerado como una entidad en sí mismo o identificado con otras divinidades. Le fueron dedicados templos en los cuales se oraba tres veces al día, cambiando la dirección de la mirada: en la mañana, hacia el oriente; a mediodía hacia el sur, y en la tarde, hacia el occidente. El primer día de la semana, dedicado al sol, fue hecho festivo por Constantino, en todo el imperio. Un día especial de consagración al dios sol habia sido establecido el 25 de diciembre, sucesivo al solsticio de invierno, que fue llamado desde esa fecha "día natal del sol invencible".

También otros pueblos adoraron al sol y le construyeron templos y cultos particulares. En la América Precolombina, los aztecas del antiguo México y los incas del Perú fueron fieles adoradores del sol.

El gran templo piramidal de la capital azteca: Tenochitlan, poseía sobre una plataforma, la piedra del sol, consistente en un monolito basáltico circular, esculpido de figuras y jeroglíficos. Al centro, aparece la máscara sufriente del dios sol, Tonatiuh, siempre sediento de sangre humana. Las figuras a su alrededor representan todoslos movimientos del astro durante 18 meses de 20 días cada uno, a sí como compleja información astronómica capaz de prever la verificación de los eclipses, particularmente temidos. Según los aztecas, el sol era escoltado hacia el cenit por las almas de los guerreros; acompañadas también por las almas de las mujeres valerosas, muertas en guerra o en el primer parto.

Antes que se desarrollara el
uso de las meridianas, había
un heraldo que anunciaba el
mediodía en el Foro de Roma;
y la hora se calculaba por la
incidencia de una cierta
sombra en un determinado
lugar del Foro. Por razones
militares, los romanos
dividieron el dia y la noche en
cuatro partes, habiéndolas
calculado sobre la base de
observaciones del sol y las
estrellas

de la selva amazónica, descubiertas por recientes expediciones, tienen al sol como símbolo predominante.

La puerta del Sol de Tiahuanaco, en Bolivia, presenta un diseñogeométrico con personajes centrales enmascarados, de ojos redondos y fijos, acaso imagen del mistico creador solar del universo. Pero según el arqueólogo chileno José Imbelloni, se trata de simples decoraciones simbólicas y el nombre dado al monumento es arbitrario. Se discute por otra parte, si son monumentos singulares o solamente decoraciones; sin embargo los cientificos están de acuerdo que constituyen la tecnología de los antiguos instrumentos empleados por el hombre para medir el tiempo y el curso del sol.

Con el desarrollo de la civilización, el hombre continuó perfeccionando su primitivo reloj de sombra, cuyo principio era prácricamente el mismo de los primerostiempos: un asta rígida, que proyecta una sombra sobre una superficie plana que previamente ha sido dividida por segmentos. Posteriormente la división de la superficie atendió la verdadera y propia subdivisión del riempo de la meridiana.

El primer reloj práctico de sombra fue inventado por los egipcios, usado del siglo $\mathrm{X}$ al VIII antes de Cristo. Consistia en una base de piedra con incisiones a los lados, representando la escala del tiempo; escala sobre la que caía la sombra dejada por el sol que, a través de un sistema de proyecciones geométricas, of recia las indicaciones del tiempo.
En el Perú, la dinastía de los Incas era considerada descendientes del sol, y por ello el culto oficial del Estado estaba unido al astro celeste. En todo el imperio incaico fueron alzados templos al sol; pero el único vestigio se encuentra en Vilcas-Huamán, al sudoeste de la antigua capital del Cuzco. La describen de tipo piramidal, con una sola puerta y una escalinata interna de 33 gradas. En la cúspide una silla de piedra, y también una sombra de oro, que acogia al Inca durante las ceremonias religiosas dedicadas al astro.

En Machu-Pichu, el famoso centro ceremonial incaico construido en la cima de la cumbre andina, se erguia también un monumento monolítico al sol. Todas las inscripciones rupestres que desde las laderas de los Andes se vuelcan dentro
Por su parte, la meridiana ha sido un instrumento universal de medición del tiempo; y en ef ecto, se encuentra en la mayor parte de las civilizaciones. Era usada en China, en diversas formas, por lo menos desde el primer siglo antes de Cristo. Se conoce la existencia de una piedra de meridiana ecuatorial del siglo III antes de Cristo, con periodos subdivididos no en horas según el sistema clásico, sino que en 100 partes iguales correspondientes cada una en 14 minutos.

El arte de la meridiana parece desaparecer al final del siglo XII, un ejemplar en uso bajo la dinastía Yuan y Ming en China, entre el 1206 y el 1644 , estaba formado de un nomon fijo, apuntando sobre la estrella polar, y de otro, móvil, que podia ser colocado en varias posiciones. El tiempo venia indicado por la coincidencia en la sombra de ambos. 


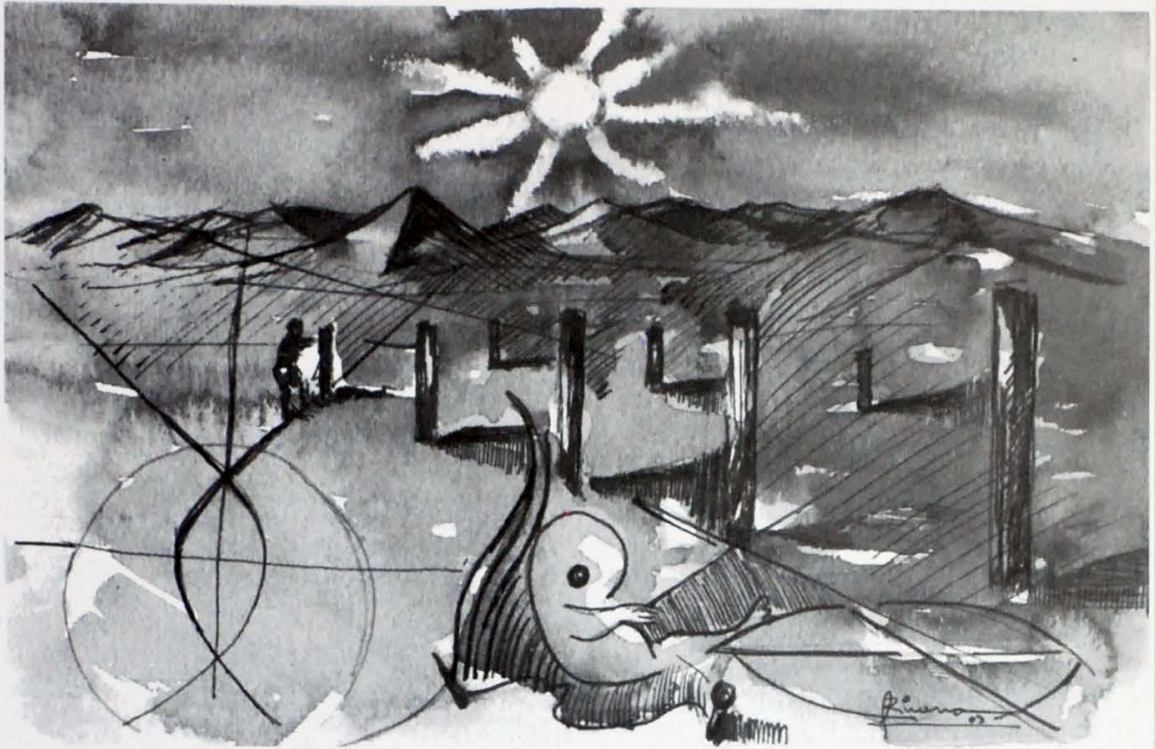

Los chinos crearon también meridianas monumentales, en piedras grabadas, referenciadas al plano ecuatorial. Eran meridianas con dos caras, cuya superficie superior era usada en los meses estivos, y la inferior en el invierno, cuando el sol estaba bajo el ecuador. La sombra del sol no aparecia en ninguna de las dos caras durante el equinoccio. Estos instrumentos eran puestos sobre pedestales, a la altura del ojo humano, y frente a los más importantes edificios públicos.

Las meridianas eran de uso común en Japón y Corea, al final del periodo de la dinastía china Han. Estos meridianos chinos fueron copiados en Japón y Corea con algunas modificaciones; asi como lo fueron las meridianas occidentales, introducidas en Europa a partir del siglo XVII.

¿Pero quién invento las horas? Regresamos al Mediterráneo y recordemos que en la Grecia de Homero, el dia estaba dividido en tres partes: del alba al mediodia, el mediodia y la tarde hasta la noche. La introducción del nomon hace posible la división del dia en partes más pequeñas, pero no se hablaba todavia de subdivisión en horas.

Según la tradición cuando la sombra tenia una cierta longirud, era la hora del baño; cuando la longitud era cl doble, era entonces la hora de la cena. Subdivisiones más precisas se iniciaron con la observación del mediodía exacto y con la división de la jornada en cuartos. Todavía con los romanos, se continuaba usando la división en cuartos, diferenciando las horas tercera, sexta y nona.

Según Herodoto, los griegos aprendieron el uso de la meridiana de los babilonios del VI siglo antes de Cristo, y de ellos viene la costumbre de dividir la jornada en doce partes. Mas tarde, los griegos mejoraron el reloj solar en varias formas. El primero fue un reloj constituido de una cavidad hemisférica en cuyo fondo era fijado el nomon. La sombra describia un circulo en la superficie interna; circulo yue variaba según las estaciones, luego esto se distribuia en doce horas para cada una de las cuatro estaciones, distribuidos en signos en una linea de las horas.

En el siglo II antes de Ciristo, los griegos mejoraron ulteriormente la meridiana. En el mismo periodo, Claudio Ptolomeo, el matemático y astrónomo de Alejandria, escribe un tratado sobre el modo de construir una meridiana, calculándola sobre bases trigonométricas.

Recientes estudios hechos por Sharon Cibbs, de la Universidad de Yale, han demostrado que la meridiana griega construida ances de la era cristiana, habian sido hechos para seguir el camino anual del sol, más que su movimiento diur- 
and(o) 110

Gitorino

entorino

entorino

Universidad Tecnologica de El Salvador entorno

entorito

entorino

entorino

entorino

enlorino

enlorino

Ai) 10 ring

s) 10710

entorina

enlorino

Anloryo

entorno

enlorino

Anloring

entorino

Antornce

entorino

entorne

entorno

entornc

entorno

entorno

entorno

Anlorito

entorno

entorno

entoring

entoring

entorno

entorno

entorno

entorno

entorno

entorno

entorno

entorno

entorno

entorno

entorna

entorna

entorno

entorno

entorno

ento

entor

entorns

entornd

entorn:

entort

entorno

entoring

\section{Gi}

no. Las construidas después de Cristo eran en su mayor parte, orientadas a seguir el movimiento solar coridiano. Los romanos aprendieron de los griegos, el conocimiento y uso de la méridiana.

Antes que se desarrollara el uso de las meridianas, había un heraldo que anunciaba el mediodía en el Foro de Roma; $y$ la hora se calculaba por la incidencia de una cierra sombra en un determinado lugar del Foro. Por razones milirares, los romanos dividieron el día y la noche en cuatro partes, habiéndolas calculado sobre la base de observaciones del sol $y$ las estrellas.

El waccensusw, el observador oticial de centinela en el Palacio del Senado, esperaba el primer aparecimiento del sol sobre ciertas columnas, y anunciaba publicamente el mediodia. De la nisma forma, según Plinio, observaba también la puesta del sol y anunciaba el tramonte. Plinio atribuye la incroducción de la meridiana en Roma al Cónsul I.. P'apirio Cursore, que habia hecho instalar una en la cima del templo de Quirinio. I )icho autor agrega que una meridiana, de probable origen griego. encontrada en (.arania después de la conquista por parte de Roma, en el 261 antes de Cristo, fue llevada a Roma por el Cónsul Valerio Messala e instalada sobre una columna vecina a las de Rostri, pero habiendo estado construida para la lacitud de Cacania, en su nueva colocación se demostró un tanto imprecisa.
La primera meridiana construida para la lacitud de Roma, se dice que fue instalada por el censor Mario Filippo en el 150 antes de Cristo; aunque ya estaban en funciones orras meridianas más toscas, según relata una poesía de Plauro.

Una interesante innovación se produce en cl uso de un obelisco egipcio construido por el Faraón P'sammaitico II (549)589 A.C.), en Heliopolis. Fue transportado a Roma por el emperador Augusto y colocado en el Campo Manio, y transformado en nomon para una meridiana con indicaciones de las horas y los vientos, grabados en el pavimento. Arruinado por las invasiones y sepultado por las ruinas de los siglos, fue desenterrado y restaurado por encomienda de P'o VI ( 1775 - 1799), levantado en el centro de la Plaza de Montecitorio, donde se encuentra actualmentc.

En el momento que se consideraba siempre más necesaria una detallada división de la jornada, aparece que los romanos habían recurrido a un mérodo utilizado por los egipcios; que dividian la jornada en doce partes, cuya longitud variaba según las estaciones y que paso a la historia como wel sistema romano".

Con la caida del Imperio Romano y el final de la civilización bizantina. los estudiosos se desplazaron a Persia y Siria, llevando consigo sus conocimientos helenísticos. La meridiana fue adoptada por los árabes, que descubrieron otros

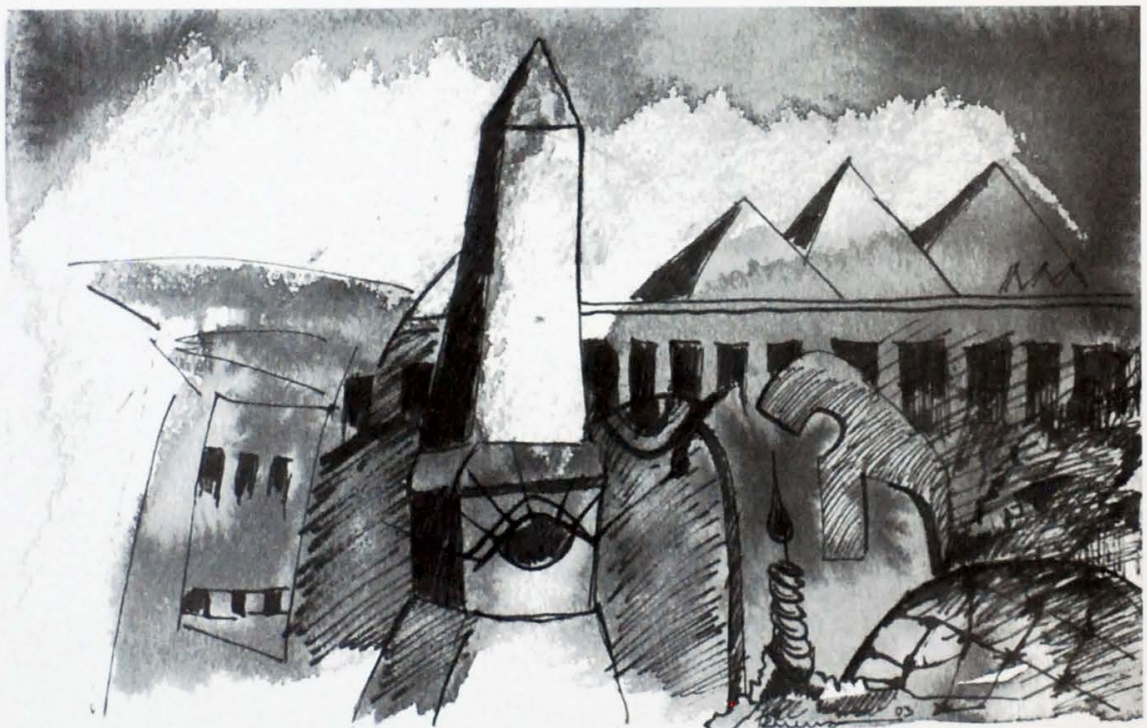


dos usos del instrumento, además de aquel de leer el riempo. En las franjas verticales sobre los muros de los parios de la mezquita estaban indicadas las horas de oración. Los árabes consiguieron construir pequeñas meridianas portátiles, llamadas kibla, que oportunamente orientadas indicaban el azimur de la kibla, la dirección de la Meca y de la kaaba (la piedra sagrada), en cualquier parte del mundo en que se encuentre el poseedor de tal instrumento.

Las guerras y las invasiones que desbastaron Europa entre el IV y el VI siglo, produjeron una sacudida de la economía y con esto el interés por la lectura del tiempo comenzó a disminuir. La Iglesia Cristiana continuó sirviéndose del meridiano para determinar la hora de la oración. la meridiana cae en desuso y permanece como un elemento decorativo, en su forma horizontal, en jardines y parques públicos. Sin embargo, de cuando en vez se fabrican algunas nuevas formas de meridianas para objetivos particulares.

Un ejemplo, muy interesante, es el inventado por Jean Baptiste Rousseau, ingeniero francés; que consiste en la llamada meridiana "cannone", erigida en los jardines del Palacio Real de Paris, en donde funciona. Varias reproducciones han sido hechas en tiempos recientes, por artesanos franceses $y$ de otros países europeos.

Otro ejemplo es el del heliocronómetro, inventado al final del siglo XX, expuesto en muchas estaciones ferroviarias francesas y suizas, para permitir a los viajeros regular sus propios relojes mecánicos. Y es bastante curioso que, no obstante los progresos de la técni$\mathrm{ca}$, hasta hace poco el sol había of recido un instrumento para corregir los errores de los relojes mecánicos.

Dispensador de vida y de luz, perfecto instrumenro para la regulación de la actividad coridiana, inspiración de los artistas, el sol verdaderamente merece la admiración que ha recibido siempre. Se ha comprobado que el sol funciona con un extraordinario proceso de fusión nuclear, que libera energia de canridad dificilmente comprensible al referirlo a la escala humana; en un segundo libera una energía tal, que todas las centrales termoeléctricas de los paises industrializados como Francia, Italia y Alemania, emplearían 300 millones de años en producir. De toda esta energía, la tierra recibe una pequeñísima fracción; pero así como es de mínima la energía emitida por el sol que la tierra recibe, es muchísima con respecto al consumo de los seres humanos.

formas de meridiana portátil, construida generalmente en madera, $y$ algunas veces en marfil, consiste en una columna cilíndrica sobre la que han sido labradas las líneas de las horas. En una extremidad está fijado un nomon replegable, de latón y una escala graduada hace de calendario.

La meridiana viene suspendida en un dedo, y el nomon, que debe proyectar la sombra, esta vuelto hacia el sol. La extremidad de la sombra cae sobre la columna e indica la hora. Este tipo de meridiana fue usado comúnmente en Europa, sobre todo en el campo, al inicio del siglo XX.

Con el progreso de la tecnología de los relojes, ya fueran de pared o de pulso; y con su enorme difusión en el mercado,
Todos los millones de seres humanos que habitan actualmente nuestro planeta, utilizan cada año, del subsuelo, cerca de 300 millones de toneladas de carbón, otras tantas de petróleo y cerca de 100 millones de toneladas de gas natural. De la combustión de todos estos materiales se liberan cada año aproximadamente $300 \mathrm{EJ}$, y por consiguiente, más de quince mil veces mayor que la que se utiliza para hacer funcionar las máquinas, producir los bienes y calentar las casas del mundo. Algunos cálculos estiman que se requeriría obtener 120,000 millones de toneladas de petróleo para obtener esta energía. 
entorno

entorno

entorno

entorno

entorno

entorno

entorno

entorno

entorno

entorno

entorno

entorno

entorno

entorno

entorno

entorno

entorno

entorno

entorno

entorno

entorno

entorno

entomo

entorno

entorno

entorno

entorno

entorno

entorno

entorine

entorno

entorno

entorno

entorno s

entorns

entornc

entorne

entorno

entorno

entorno

entorno

entorno

entorno

entorno

entorno

entorno

entorns

entoring

entorno

entorno

entornc

entornc

entornd

entoric

entorno

Gilotino clorofilica, sobre la superficie de los continentes, en los ma-

Una parte de la energía solar viene reflejada de la atmósfera, y el resto, aproximadamente $3.500,000 \mathrm{EJ}$ al año, arriban sobre la superficie del planera, sus mares y sus continentes, después de haber atravesado la atmósfera.

En las varias estaciones del año, la intensidad de la radiación solar que alcanza las diversas partes de la Tierra es muy diferente, y este desigual calentamiento de hatmósfera y de la superficie terrestre provoca la formación de los vientos y el ciclo del agua.

La radiación solar es el gran motor de todo cuanto sucede en al Tierra y de todas las formas de vida. Ello se debe no solamente a la gran cantidad de energía irradiada del sol, sino también del tipo, es decir de "la calidad" de la energía que arriba sobre la Tierra.

La energía del sol tiene en movimiento, a través de la atmósfera, cada año, $\mathbf{4 0 , 0 0 0}$ millones de metros cúbicos de agua que se evaporan de los océanos y de los continentes, para volver a caer, lejos, bajo la forma de lluvias, sobre la superficie de los mares y de las tierras emergidas en la superficie del planeta. 100,000 millones de metros cúbicos de esta agua corren sobre la superficie de los continentes y regresan al mar; suministrando agua a los seres humanos, es también energía hidrica e hidroeléctrica. La energía del sol, calentando diversamente las varias partes de la atmósfera y de la superficie de la tierra, pone en movimiento grandes masas de aire que originan los vientos, y en consecuencia, el movimiento ondular. entorno

entoEntorno

Apuntes breves y maravillosos sobre el sol

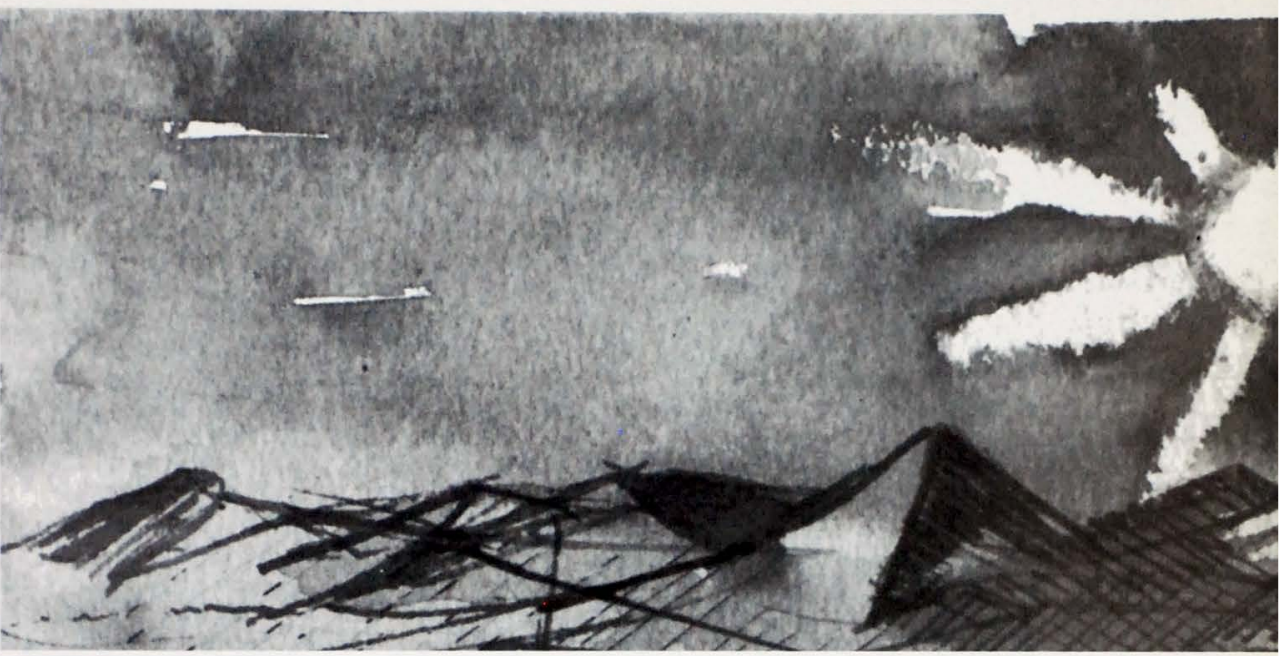

res y océanos, cerca de 500 millones de toneladas de sustancias orgánicas, equivalentes en contenido energético a cerca de 2,000 EJ. al año. En esta forma se producen, desde hace 300 millones de años, las sustancias orgánicas que son transformadas, en periodos que comprenden millares de siglos, en combustibles fósiles, carbón, perróleo, gas natural, que constituyen la casi totalidad de las fuentes energéticas utilizadas actualmente y de las que existen reservas que ascienden a aproximadamente $300,000 \mathrm{EJ}$.

El ciclo natural del agua es una de las más importantes consecuencias de la energía solar. la tierra tiene una superficie de casi 510 millones de kilómetros cuadrados; de los cuales, dos tercios, que significan aproximadamente 360 millones de kilómetros cuadrados, están cubiertos de agua. La cantidad total de agua existente sobre la Tierra se estima en 1400 millones de millones de metros cúbicos; la mayor parte depositada en los océanos.

El agua sobre la Tierra está en continuo movimiento; calentada por la energía solar, el agua se evapora de la superficie de los océanos, mares, lagos y ríos; también se evapora una parte del agua que se encuentra en los estratos superficiales del terreno y parte de la que se encuentra en las hojas, los vegetales y los animales: el fenómeno en este caso se llama evapo- transpiración. En el proceso de evaporación, el agua se sustrae del agua del ambiente, del aire, del terreno, de la superficie de las hojas, produciendo una gran cantidad de calor; la misma cantidad de calor que el vapor acúeo restituye en el momento de la condensación.

El agua que se evapora se mezcla, en ese estado, con el gas de la atmósfera; y el vapor acuoso tiende a ubicarse en los estra- 
entorno

entorno

entorno

entomo

entorno

entorno

entorno

entorno

entorno

entorno

entorno

entorno

entorno

entorno

entorno

entorno

entorito

entorino

entorino

entorno

entorine

entorino

entorino

entorno

entorino

einlonito

entorino

entorno

entorne

entorine

entomo

entorno

entario

entorno

entorine

entorno

entorno

entorito

entorino

entorno

entorno

entorne

entorno

entorino

entorno

entorno

entorno

entorno

ento

entorno

entorino

entorno

entorno

entorn

entorino

entorno

sultentor

entontorno

El sol pone a disposición de la humanidad una grandisima reserva de energia hidrica; desdichadamente los grandes rios y las grandes montañas estan en zonas deshabitadas, como las zonas tropicales y ecuatoriales, Groenlandia y Asia Central. Es posible que un dia, estas zonas atraigan industrias y ciudades, of reciendo energía limpia y prácricamente interminable.

() tra de las maravillosas manifestaciones del sol, la más sorprendente de rodas, está constituida por su capacidad de transformar algún gas en materia sólida, combustible en las células verdes. En un establecimiento químico, que produce por ejemplo, amoníaco sintérico o materias primas plásticas, se introducen las materias primas y con la cooperación de la energía, se obrienen los productos finales. En corno a nosorros, millares de millares de microscópicos establecimientos químicos, con una generosidad increible, producen sustancias combusribles bajo nuestros ojos, en los jardines, en los campos y en las macetas sobre las terrazas. Las materias primas, gratuitas, son el anhidrido carbónico presente en la atmósfera, a razón

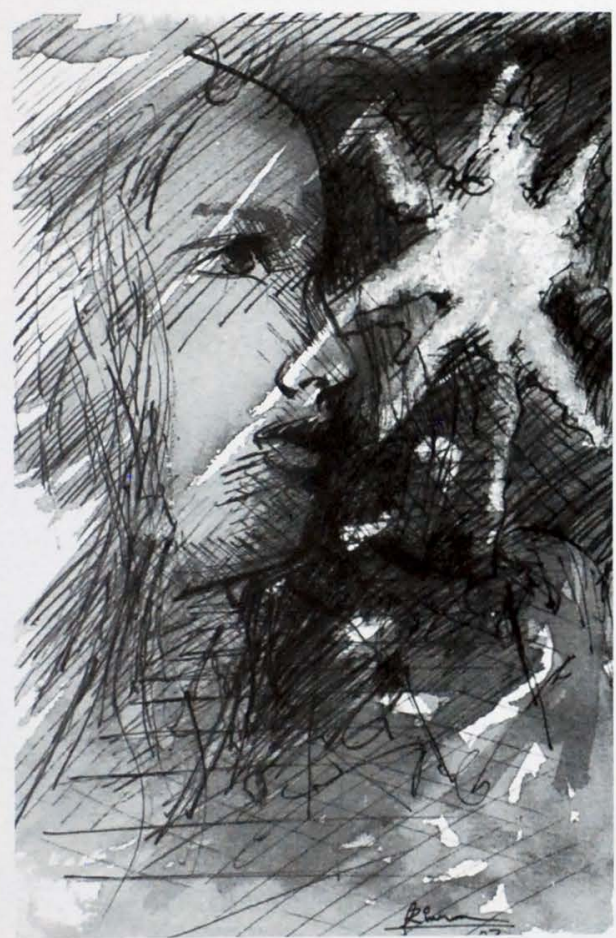

ISSN: 2218-3345

Apuntes breves y maravillosos sobre el sol

de $\mathbf{4 5 0}$ milímetros cúbicos por cada metro cúbico de aire, y el agua que las células contienen en su interior.

La célula de las plantas está dotada de un especial material químico, llamado clorofila, de color verde, que sin estar involucrando directamente en la reacción de sintesis; consiente a la energía solar para combinar el anhidrido carbónico y el agua, con formación de combustible sólido y liberación de oxigeno, al mismo tiempo. No obstante la apariencia contraria, de la fotosíntesis vegetal, provocada por la luz en juego; es decir, de la radiación luminosa solar, tenemos nociones muy limitadas. Conocemos el consumo de energía; tenemos alguna idea de las reacciones quimicas, que varian de planta a planta; y que llevan a la formación de las moléculas orgánicas, azúcar, almidones, proteinas, celulosa: es decir, la materia o biomasa vegetal.

Bajo nuestros ojos, las plantas aumentan de peso algunos gramos al dia y hectáreas de bosques, aumentan de peso en el periodo de un año, por varias toneladas. La fotosíntesis clorofilica fabrica biomasa en razón de 5000 millones de toneladas al año, no solamente sobre la tierra, sino también en los ríos, mares y océanos. Esta extraordinaria función de la energía del sol, debe haber sorprendido a los ecólogos del siglo pasado, que asignaron a los organismos vegetales, el nombre de "organismos productores", tomado en préstamo de las fäbricas y de la economía.

Los animales y nosotros mismos, los orgullosos habitantes del planeta Tierra, dependemos de los vegetales para nuestra vida y hemos sido clasificados por los ecólogos, también con otro termino prestado de la economia: "organismos de consumo". Los seres humanos, juntamente con todos los animales, pueden sobrevivir nutriéndose de una fracción del sol, aprisionada en las plantas.

Si solamente tuviéramos una idea de cómo funcionan verdaderamente los vegetales; si nosotros nos decidiéramos a copiar el mecanismo de la forosintesis, tendríamos a nuestra disposición una fuente alimenticia de energía. La sugerencia es tan importante, que prestigiosos científicos están dedicados al estudio de estas maravillas. Entre ellos, Melvin Calvin, ha obtenido un Premio Nóbel por sus contribuciones al conocimiento de la sintesis clorofilica.

El sol, dador de luz y vida, fuente de inspiración de profetas y poetas, es aún un misterio pese a la proliferación de estudios cientificos hechos para conocerlo y entenderlo. 